\title{
A utilização de novos sistemas construtivos para a redução no uso de insumos nos canteiros de obras: Light Steel Framing
}

\author{
Adopting new construction systems to reduce the use of \\ resources in construction sites: Light Steel Framing
}

\section{Hylton Olivieri \\ Ivan Carlos Alves Barbosa \\ Antonio Carlos da Rocha \\ Ariovaldo Denis Granja \\ Patricia Stella Pucharelli Fontanini}

\section{Resumo}

A

utilização de novos sistemas construtivos pode representar reduções consideráveis no uso de insumos e operações nos canteiros de obras, tais como menor consumo de mão de obra na produção, redução na geração de resíduos, otimização da logística local, menor consumo de água e redução dos prazos de obra. Nesse contexto, o sistema Light Steel Framing (LSF) apresenta-se como um processo de grande potencial quando utilizado como um sistema construtivo para a produção de fachadas, em substituição ao sistema tradicional, composto de alvenaria de vedação e revestimento externo aderido, principalmente em edifícios com múltiplos pavimentos. O objetivo deste trabalho é comparar o LSF e o sistema tradicional de produção de fachadas, considerando-se quantitativamente a utilização de mão de obra, geração de resíduos, consumo de água e prazos de obra, por meio da análise de quatro estudos de caso em dois países (Brasil e Alemanha), que consideram empreendimentos para fins de moradia permanente ou temporária. As principais contribuições deste estudo estão relacionadas aos índices de consumo de mão de obra do LSF, apurados a partir dos

Hylton Olivieri Aalto University Espoo - Finland

Ivan Carlos Alves Barbosa Rossi Residencial S/A São Paulo - SP - Brasil

Antonio Carlos da Rocha ACR Assessoria e Planejamentos Ltda. São Paulo - SP - Brasil

Ariovaldo Denis Granja Universidade Estadual de Campinas Campinas - SP - Brasil

Patricia Stella Pucharelli Fontanini Universidade Estadual de Campinas Campinas - SP - Brasil

Recebido em 22/03/17 Aceito em 25/07/17 estudos de caso, além de suas potenciais vantagens em comparação ao sistema tradicional.

Palavras-chave: Light Steel Framing. Sistemas construtivos. Novas tecnologias. Fachadas. Insumos.

\section{Abstract}

Adopting new technologies in construction systems may lead to considerable reductions in the use of resources and operations in construction sites, such as less production labour, a decrease in material waste, improvements in logistics, a reduction in water consumption and less time spent on construction. In this context, Light Steel Framing (LSF) is considered a process with great potential when used as a façade system, mainly in multi-storey buildings, replacing the traditional method, which uses brick block masonry and external plaster. The aim of this research is to compare LSF with the traditional façade system quantitatively, considering labour, material waste, water consumption and construction time, using four cases studies in two countries (Brazil and Germany), which consider housing projects. The main contributions of this study are related to labour consumption rates when using LSF, obtained from case studies, as well as their potential advantages when compared with the traditional system.

Keywords: Light Steel Framing. Construction systems. New technologies. Façades. Resources.

OLIVIERI, H.; BARBOSA, I. C. A.; ROCHA, A. C. da; GRANJA, A. D.; FONTANINI, P. S. P. A utilização de novos sistemas 45 construtivos para a redução no uso de insumos nos canteiros de obras: Light Steel Framing. Ambiente Construído, Porto Alegre, v. 17, n. 4, p. 45-60, out./dez. 2017. 


\section{Introdução}

A utilização de novos sistemas construtivos pode representar reduções significativas no uso de insumos e operações nos canteiros de obras. No cenário brasileiro, entretanto, tem sido uma cultura do setor de construção a utilização de processos tradicionais em detrimento às tecnologias mais avançadas, gerando-se improvisações nos canteiros e baixa eficiência na utilização de recursos (GOMES; SOUZA; TRIBESS, 2013). Um dos fatores que podem contribuir para facilitar a implementação de novas tecnologias é a apresentação de seu impacto nos custos de um empreendimento. Nesse cenário, o sistema de produção de fachadas merece destaque, visto que pode representar de $15 \%$ a $20 \%$ dos custos totais (MEJICOVSKY; SETTLEMYRE, 2003), incluindo vedações externas, esquadrias, revestimentos em argamassa, revestimentos em gesso e acabamentos.

O sistema construtivo Light Steel Framing (LSF) é um sistema caracterizado pelo uso de perfis leves de aço zincado formados a frio, compondo estruturas esbeltas vedadas com painéis ou chapas industrializadas (MEDEIROS et al., 2014), e vem sendo empregado em larga escala em países desenvolvidos, seja como elemento de vedação externa ou como elemento estrutural autoportante, montado in-loco no canteiro de obras ou préfabricado em módulos (VELJKOVIC; JOHANSSON, 2006; LAWSON; OGDEN, 2008). Historicamente, elementos de aço como o LSF têm sido utilizados em construções residenciais há mais de 70 anos (LAWSON; OGDEN, 2008). No Brasil, apesar de barreiras culturais (VIVAN; PALIARI, 2012), a utilização do LSF vem crescendo nos últimos anos, principalmente como elemento de vedação externa e na construção de habitações unifamiliares, hospitais, escolas, edifícios de até quatro pavimentos e retrofit de edificações existentes (FREITAS; CRASTO, 2006). Recentemente, o LSF tem sido usado no mercado como uma alternativa inovadora para a execução de fachadas em edifícios de múltiplos pavimentos (SANTIAGO; ARAÚJO, 2008; CARDOSO, 2016; ROCHA, 2017), substituindo o processo tradicional por uma tecnologia mais ágil.

Neste trabalho, o LSF é definido como um sistema para a produção de fachadas, aplicado em empreendimentos com estruturas de concreto armado ou metálicas (SANTIAGO, 2008), sendo composto de:

(a) camada de estruturação (perfis metálicos leves); (b) camada externa (chapas delgadas, perfis para juntas de dilatação e proteção, telas em fibra de vidro e massas de base cimentícia para tratamento de juntas e revestimento externo);

(c) camada impermeável (membrana de polietileno para estanqueidade e prevenção de condensação no interior da fachada);

(d) camada isolante (manta para isolamento térmico e acústico); e

(e) camada interna (placas de gesso acartonado) (CARDOSO, 2016).

Além disso, define-se o processo tradicional para produção de fachadas como o sistema construtivo constituído por vedações verticais externas em blocos de concreto ou cerâmicos, aplicação de chapisco e argamassa cimentícia externa, tratamento de juntas de dilatação e revestimento interno em gesso liso.

Quando comparados aos sistemas tradicionais, os sistemas com maior grau de industrialização, tais como o LSF, tendem a proporcionar melhorias nas operações dos canteiros de obras, tais como uma expressiva redução de mão de obra e melhorias nas condições de logística interna dos canteiros (VIVAN; PALIARI, 2012; ROCHA， 2017), economizando espaço para o armazenamento de material no local, o que acarretaria em um melhor controle de qualidade da produção, redução de desperdício e possibilidade de um gerenciamento de cadeia de suprimentos mais eficiente (BABIČ et al., 2010). Entretanto, os sistemas industrializados usualmente requerem etapas preliminares de préfabricação, por vezes realizadas antes mesmo do início das obras, o que exige planejamento e projetos executivos com maior grau de detalhamento (SILVA; BARROS, 2012), além de eventual antecipação de despesas financeiras, principalmente para o caso de sistemas com grande quantidade de elementos pré-fabricados.

No Brasil ainda predominam as tradicionais alvenarias em blocos de concreto ou cerâmicos e revestimentos em argamassa, com lançamento manual ou mecânico (ZANELATTO; BARROS; SABBATINI, 2013; ROCHA, 2017). Além disso, profissionais e empresas que se propõem a implementar o LSF no mercado nacional têm encontrado dificuldades como:

(a) o custo direto mais alto do sistema construtivo LSF em relação ao sistema tradicional, devido à baixa demanda do mercado para a tecnologia, que utiliza diversos componentes importados;

(b) para a instalação do LSF com montagem in loco, os fornecedores disponíveis no mercado não 
oferecerem o sistema construtivo em sua completude (fornecimento e montagem), mas sim um "sistema de produto" em que os componentes são comercializados separadamente e para o qual se deve contratar mão de obra de um terceiro especializado na montagem do sistema no canteiro; e

(c) incertezas quanto à ocorrência de patologias, assim como a baixa especialização dos profissionais em projetar e planejar a produção da tecnologia, adequando-a aos demais subsistemas da edificação (ROCHA, 2017).

Sendo assim, justifica-se a necessidade por trabalhos que discutam o LSF, particularmente com foco nos fatores que tipicamente $o$ caracterizam quando comparado aos sistemas tradicionais, tais como maior produtividade da mão de obra, redução do prazo da obra, menor geração de resíduos e reduzido consumo de água.

Além de contribuir com a apresentação de índices de consumo de mão de obra do LSF, o objetivo deste trabalho é comparar o LSF com o sistema tradicional de produção de fachadas, considerandose os aspectos de mão de obra, geração de resíduos, consumo de água e prazos de obra. Para este intento, as evidências foram coletadas de quatro estudos de caso em dois países, Brasil e Alemanha, que consideram empreendimentos para fins de moradia permanente ou temporária. Essas evidências também foram utilizadas com o objetivo de validar as seguintes proposições:

(a) o LSF contribui para a redução do consumo de mão de obra nos canteiros;

(b) a partir da utilização do LSF, obtém-se redução na geração de resíduos dos materiais utilizados durante o processo construtivo;

(c) por ser um sistema que utiliza componentes semi-industrializados e padronizados acoplados a seco, o LSF reduz o consumo de água nos canteiros de obras; e

(d) o LSF pode contribuir para a redução dos prazos de obra.

\section{Light Steel Framing (LSF)}

Um corte esquemático mostrando as camadas interna e externa do LSF, além da indicação dos principais elementos que compõem o sistema, é apresentado na Figura 1. Em relação a sua utilização em fachadas, o LSF pode ser:

(a) montado in-loco, com os elementos que compõem o sistema sendo entregue no canteiro e montados um a um, requerendo uma maior quantidade de mão de obra no local, o que por vezes pode apresentar distorções de produção dependendo da equipe responsável pela montagem;

(b) pré-montados no canteiros, com os elementos principais, tais como guias e montantes, em área específica e transportados até o local da aplicação, onde as demais etapas que compõem o sistema são aplicadas; e

(c) pré-fabricados em formato de painéis com todos os elementos que compõem o sistema, em fábrica específica ou no próprio canteiro de obras, sendo apenas fixados à estrutura principal da edificação.

Este último método consome uma quantidade menor de mão de obra para montagem, quando comparada aos outros processos de montagem, porém requerendo equipamentos para sua movimentação e montagem, tais como gruas e guindastes. Neste trabalho, adotou-se a premissa de utilização do LSF como elemento montado in loco, característica também presente nos estudos de caso analisados.

Em comparação ao processo tradicional, o LSF apresenta vantagens como a utilização de materiais leves e recicláveis (VIVAN; PALIARI, 2012), possibilitando melhor reaproveitamento dos resíduos, melhor eficiência na utilização de mão de obra, devido a seu maior grau de industrialização (WAY; LAWSON, 2013) e melhoria nas condições de logística do canteiro de obras (PÉREZ; COSTA; GONÇALVES, 2016), para permitir uma área menor de estocagem e uma quantidade menor de movimentação de equipamentos de transporte vertical, como guinchos-cremalheira (ROCHA, 2017). De forma complementar, autores como Way e Lawson (2013), Soares et al. (2014) e Rocha (2017) apresentam como vantagens do LSF a redução dos prazos totais de construção, a utilização mais eficiente dos recursos de mão de obra, a diminuição de problemas operacionais no canteiro, a alta taxa de reciclagem de seus elementos, o baixo peso próprio do sistema e o bom desempenho térmico, acústico e de resistência ao fogo.

No Brasil a principal referência sobre o sistema de fachada LSF é a Diretriz Sinat 009 (BRASIL, 2016), que contém as condições, requisitos, critérios e ensaios para a avaliação técnica do sistema. Entretanto, por ser um sistema inovador e recentemente introduzido no mercado nacional, há escassez de publicações científicas sobre o assunto, principalmente trabalhos que apresentem os potenciais benefícios e os desafios para a utilização do LSF em detrimento do processo tradicional. 
Figura 1 - Sistema Light Steel Framing aplicado na produção de fachadas

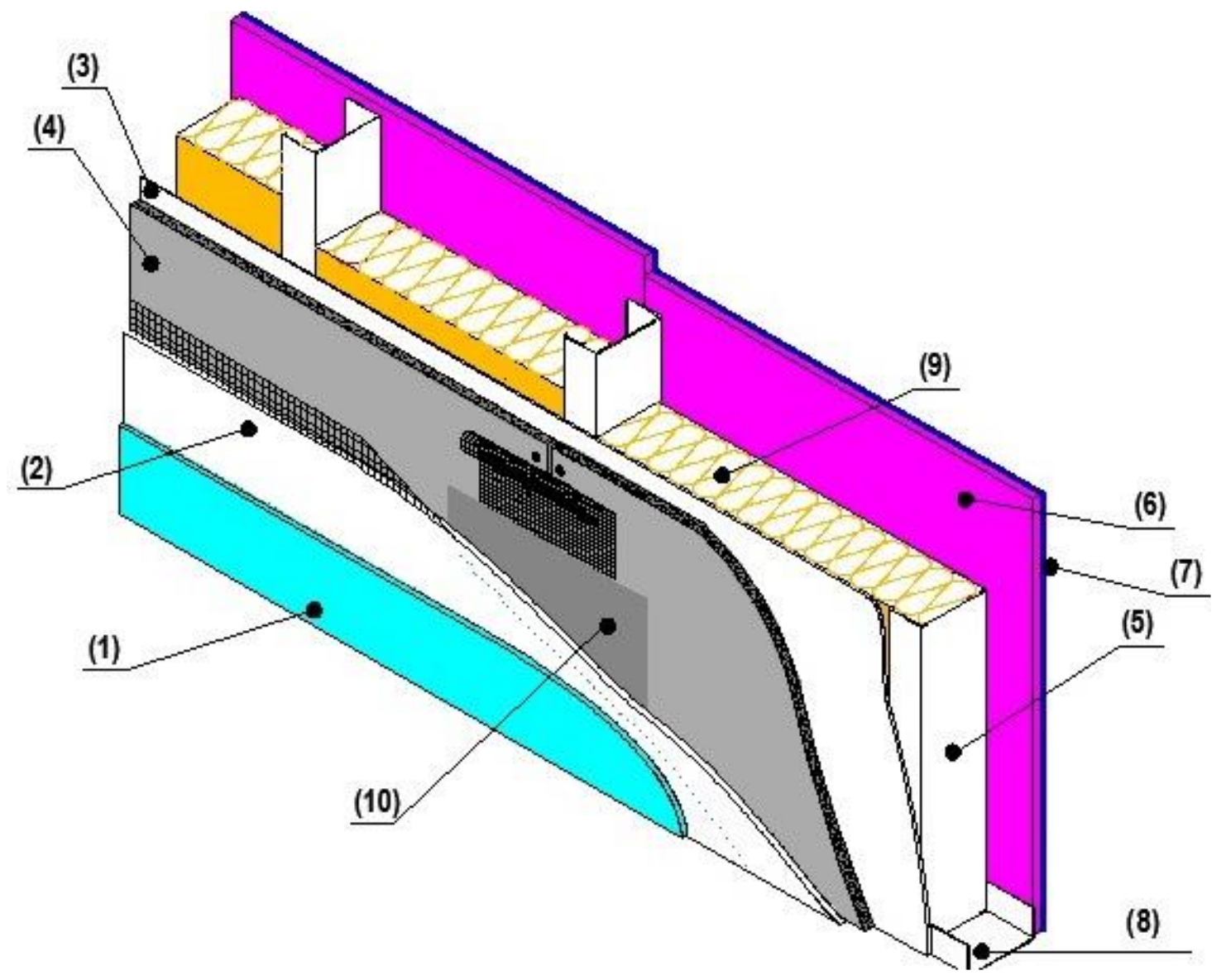

Fonte: adaptado de Brasil (2016).

Nota: Legenda: 1) Camada de acabamento externo; 2) Basecoat (argamassa à base de cimento e resina acrílica) com malha de reforço em fibra de vidro: camada de revestimento externo aplicada sobre $100 \%$ das chapas cimentícias; 3 ) Camada impermeável: membrana que funciona como barreira de vapor, impedindo a proliferação de umidade no interior do sistema; 4) Chapa cimentícia: elementos de vedação externa acoplados aos perfis metálicos; 5) Montantes: perfis metálicos instalados no sentido vertical que possuem função de estruturação do sistema; 6) Chapas (duplas) de gesso acartonado $15 \mathrm{~mm}$ resistentes ao fogo: elementos de vedacão interna acoplados aos perfis metálicos da estrutura em LSF; 7) Camada de acabamento interno; 8) Guias: perfis metálicos instalados no sentido horizontal sob vigas e lajes, na parte superior do pavimento, e sobre a laje de piso do pavimento, com a função de determinar o correto posicionamento para a instalação do sistema; 9) Camada de isolamento termoacústico; 10) Malha de reforço em fibra de vidro com enchimento argamassado (cimento-acrílico) aplicado sobre juntas das placas cimentícias.

\section{Método de pesquisa}

A estratégia de pesquisa adotada para o desenvolvimento deste trabalho foi o estudo de caso: uma investigação empírica na qual se investiga um fenômeno contemporâneo em profundidade e em seu contexto de vida real, especialmente quando os limites entre o fenômeno e o contexto não são claramente evidentes (YIN, 2013). A escolha dos casos se deu com base no preenchimento de critérios de importância previamente estabelecidos (PATTON, 1990). Esta abordagem na seleção dos casos é comumente associada às tentativas de garantia de qualidade na condução dos estudos de caso (PATTON, 1990).
Os seguintes critérios foram adotados na seleção dos casos:

(a) eles deveriam estar relacionados a empreendimentos para fins de moradia permanente ou temporária, com múltiplos pavimentos;

(b) deveriam utilizar o LSF como sistema de fachada principal;

(c) o LSF deveria ser montado in loco; e

(d) deveriam conter dados que permitissem a geração de índices de consumo de mão de obra.

Ainda foram considerados estudos de caso desenvolvidos em dois países (Brasil e Alemanha) a fim de se contemplar a triangulação de evidências (YIN, 2013; TUZZO; BRAGA, 2016). 
A seguir apresentam-se os estudos de caso selecionados:

\section{(a) estudo de caso A: empreendimento} residencial localizado no Estado do Rio de Janeiro, Brasil, construído entre os anos de 2013 e 2015, com estrutura de concreto armado como elemento estrutural. $\mathrm{O}$ empreendimento contém quatro torres residenciais, com sete pavimentos cada torre. Uma torre possui oito apartamentos por pavimento (torre IV), e as demais possuem dez apartamentos por pavimento (torres I, II e III). A área total de fachadas em que foi aplicado o sistema LSF é de aproximadamente $15.000 \mathrm{~m}^{2}$. Na análise de redução do consumo de mão de obra foram utilizados dados coletados em campo das torres I e III. Nas análises de redução da geração de resíduos e consumo de água foram utilizados dados referentes às quatro torres;

(b) estudo de caso B: empreendimento para fins de moradia estudantil localizado na cidade de Heidelberg, Alemanha, construído no ano de 2014 pelo sistema de paredes de concreto armado, moldadas no local. O empreendimento contém três torres, sendo duas com dez pavimentos e uma torre com treze pavimentos. No total, o empreendimento possui $20.000 \mathrm{~m}^{2}$ de área construída e $800 \mathrm{~m}^{2} \mathrm{de}$ fachada com o sistema LSF, o qual foi aplicado nos dois primeiros pavimentos de cada torre, em trechos externos específicos nas fachadas frontais;

(c) estudo de caso $C$ : empreendimento de hotelaria localizado na cidade de Porto Alegre, Brasil, construído no ano de 2014, tendo estruturas metálicas como elemento estrutural. $\mathrm{O}$ empreendimento é composto de torre única, com sete pavimentos e 147 quartos. Empregou-se em toda a fachada o sistema LSF, com exceção da caixa de escada externa, localizada em uma das extremidades da torre, a qual foi construída em alvenaria de blocos de concreto a fim de se atenderem os requisitos da legislação local; e

(d) estudo de caso $\mathbf{D}$ : estudo de viabilidade realizado por uma incorporadora de grande porte, posicionada entre as 10 maiores construtoras do Brasil, de acordo com o Ranking ITC (RANKING..., 2016), que teve por objetivo viabilizar a implementação do LSF em seus empreendimentos no Brasil. Compreende uma torre única, com dezoito pavimentos-tipo e oito apartamentos por andar, num total de $17.190 \mathrm{~m}^{2} \mathrm{de}$ área construída e $8.032 \mathrm{~m}^{2}$ de fachada com o sistema LSF. O estudo de viabilidade apresenta uma comparação teórica entre os sistemas tradicional e LSF, visto que o empreendimento não foi implementado pela empresa em sua totalidade. Assim, assume-se como limitação desta pesquisa que os resultados obtidos a partir deste estudo podem sofrer variações quando coletados em situações reais. $\mathrm{Na}$ análise de redução do consumo de mão de obra e prazos foram utilizados dois cronogramas físicos planejados (tradicional e LSF) desenvolvidos pela empresa. Nas análises de redução da geração de resíduos e consumo de água foram utilizados dados quantitativos provenientes do orçamento executivo (planejado) desenvolvido pela empresa, além de índices obtidos com fornecedores e com a incorporadora responsável pelo estudo.

Uma breve descrição dos casos, as características, os objetivos do estudo e a abordagem utilizada para a coleta de dados estão descritos no Quadro 1. Relatórios técnicos de consultores e fornecedores, projetos executivos estruturais e de vedações, instruções técnicas, websites, cronogramas físicos planejados, cronogramas de suprimentos planejados, orçamentos executivos planejados (contendo composições de mão de obra, materiais e equipamentos detalhadas) e material técnico de fornecedores foram acessados, em formato eletrônico e impresso.

Profissionais que tiveram atuação nos estudos de caso, tais como diretores e gerentes técnicos, fornecedores de materiais, subcontratados de mão de obra e integrantes das equipes técnicas dos empreendimentos, foram entrevistados por meio de entrevistas semiestruturadas. Essas entrevistas contiveram questões com o objetivo de levantar os principais benefícios do LSF na utilização em edifícios para fins de moradia, além de dados referentes ao consumo de mão de obra.

Durante um período de dois anos foram realizadas visitas aos canteiros de obras dos estudos de caso A, B e C a fim de se realizarem observações em campo, coletar dados de consumo de mão de obra junto às equipes dos empreendimentos e obter informações sobre os processos de viabilidade, projeto e produção do LSF. Em complemento, o estudo de viabilidade considerado no estudo de caso D foi analisado por um comitê multidisciplinar que contou com a participação de diversos profissionais da empresa, além de pesquisadores, consultores e projetistas, avaliandose os resultados e o potencial de utilização do sistema. Sempre que possível, utilizou-se a triangulação na análise de dados de consumo de mão de obra com o objetivo de associarem-se dados semelhantes entre os estudos de caso (TUZZO; BRAGA, 2016), comparando-os com dados obtidos do sistema tradicional.

Nas análises de redução de mão de obra, geração de resíduos e consumo de água foram consideradas apenas as atividades inerentes aos dois sistemas (tradicional e LSF). Na análise dos prazos, além 
das atividades inerentes aos dois sistemas, foram consideradas atividades integrantes do caminho crítico nos cronogramas analisados e impactadas pela adoção do LSF, tais como estrutura de concreto, instalações hidráulicas e acabamentos. Dados obtidos com montadores especializados na instalação do LSF, além dos projetos de vedações e materiais técnicos de fornecedores analisados, permitiram o entendimento sobre quais dispositivos presentes no sistema LSF permitem sua instalação em obras com desaprumo da estrutura de até $4 \mathrm{~cm}$, sem a necessidade de elementos adicionais e sem impactos gerados na produtividade da mão de obra. Nos quatro estudos de caso analisados o desaprumo não extrapolou os $4 \mathrm{~cm}$ permitidos, ou seja, as situações de desaprumo para os quatro estudos foram consideradas semelhantes, sem impactos relevantes na produtividade.

\section{Quadro 1 - Descrição dos estudos de caso e coleta de dados}

\begin{tabular}{|c|c|c|c|}
\hline $\begin{array}{l}\text { Estudo } \\
\text { de caso }\end{array}$ & Objetivos & Coleta de dados & $\begin{array}{c}\text { Informações obtidas sobre } 0 \\
\text { LSF }\end{array}$ \\
\hline $\mathbf{A}$ & $\begin{array}{l}\text { Redução do } \\
\text { consumo de } \\
\text { mão de obra; } \\
\text { menor } \\
\text { geração de } \\
\text { resíduos; } \\
\text { redução do } \\
\text { consumo de } \\
\text { água }\end{array}$ & $\begin{array}{l}\text { Entrevista com a diretora do } \\
\text { empreendimento; quatro visitas ao canteiro } \\
\text { de obras, sendo três durante a fase de } \\
\text { montagem do LSF e uma durante a fase de } \\
\text { acabamentos finais; análise de documento } \\
\text { com a descrição executiva do } \\
\text { empreendimento; análise de projetos } \\
\text { executivos de estrutura e vedações, } \\
\text { cronograma físico (planejado) e orçamento } \\
\text { executivo (planejado); análise de material } \\
\text { técnico de fornecedores }\end{array}$ & $\begin{array}{l}\text { Consumo de mão de obra, a } \\
\text { partir de dados fornecidos pela } \\
\text { equipe técnica do } \\
\text { empreendimento e pelas } \\
\text { empresas subcontratadas; } \\
\text { quantidade de caçambas } \\
\text { utilizadas para o descarte de } \\
\text { resíduos; quantidade } \\
\text { (medidas) de serviços } \\
\text { referentes às fachadas }\end{array}$ \\
\hline B & $\begin{array}{l}\text { Redução do } \\
\text { consumo de } \\
\text { mão de obra }\end{array}$ & $\begin{array}{l}\text { Entrevista com o diretor e o gerente técnico } \\
\text { responsáveis pelo empreendimento; visita à } \\
\text { fábrica responsável pela produção dos } \\
\text { materiais; visita ao canteiro de obras } \\
\text { durante a fase de montagem do LSF; } \\
\text { análise de projetos de arquitetura e } \\
\text { cronograma físico (planejado) }\end{array}$ & $\begin{array}{l}\text { Composição das equipes } \\
\text { responsáveis pela montagem, } \\
\text { a partir de observação no } \\
\text { canteiro de obras; consumo de } \\
\text { mão de obra, a partir das } \\
\text { entrevistas e observações no } \\
\text { canteiro }\end{array}$ \\
\hline $\mathbf{C}$ & $\begin{array}{l}\text { Redução do } \\
\text { consumo de } \\
\text { mão de obra }\end{array}$ & $\begin{array}{l}\text { Entrevista com a equipe técnica } \\
\text { responsável pelo LSF no empreendimento; } \\
\text { duas visitas ao canteiro de obras durante a } \\
\text { fase de montagem do LSF; análise de } \\
\text { projetos de arquitetura e cronograma físico } \\
\text { (planejado) }\end{array}$ & $\begin{array}{l}\text { Consumo de mão de obra, a } \\
\text { partir de dados fornecidos pela } \\
\text { equipe técnica e pela equipe } \\
\text { de produção }\end{array}$ \\
\hline D & $\begin{array}{l}\text { Redução do } \\
\text { consumo de } \\
\text { mão de obra; } \\
\text { menor } \\
\text { geração de } \\
\text { resíduos; } \\
\text { redução do } \\
\text { consumo de } \\
\text { água; } \\
\text { redução de } \\
\text { prazos }\end{array}$ & $\begin{array}{l}\text { Análise do estudo de viabilidade realizado, } \\
\text { que contém relatórios técnicos de } \\
\text { consultores, orçamentos executivos } \\
\text { planejados (tradicional e LSF), } \\
\text { cronogramas físicos planejados (tradicional } \\
\text { e LSF) e cronogramas de suprimentos } \\
\text { planejados; entrevista com fornecedores de } \\
\text { materiais; duas entrevistas com } \\
\text { representantes de empresas especializadas } \\
\text { na aplicação do LSF; participação de dois } \\
\text { autores deste trabalho no comitê de } \\
\text { avaliação promovido pela incorporadora } \\
\text { responsável pelo estudo; análise de } \\
\text { material técnico de fornecedores }\end{array}$ & $\begin{array}{l}\text { Prazos detalhados através das } \\
\text { durações das atividades, } \\
\text { sequenciamento construtivo e } \\
\text { insumos considerados; } \\
\text { consumo de mão de obra, a } \\
\text { partir de informações obtidas } \\
\text { nas empresas especializadas; } \\
\text { quantidade e consumo de } \\
\text { materiais planejados para a } \\
\text { execução das fachadas; dados } \\
\text { de geração de resíduos obtidos } \\
\text { com um subcontratado } \\
\text { especializado }\end{array}$ \\
\hline
\end{tabular}


Em relação à produtividade de mão de obra, utilizou-se o indicador Razão Unitária de Produção (RUP) (SOUZA, 2006), calculado a partir de RUP $=\mathrm{Hh} / \mathrm{QS}$, sendo que Hh representa a mensuração do esforço humano despendido, em homens-hora, e QS representa a quantidade de serviço, calculada em metro quadrado no presente trabalho. $\mathrm{Na}$ prática, a RUP pode ser calculada diariamente, sendo o somatório de todos os dias denominado de RUP cumulativa, que representa a eficiência acumulada ao longo de todo o período de realização da atividade (SOUZA, 2006). Neste trabalho adotou-se o termo técnico RUP como sinônimo do resultado cumulativo, ou seja, a produtividade média obtida a partir da coleta de dados.

As RUPs obtidas a partir da implementação do LSF foram comparadas com a RUP do sistema tradicional. Para a obtenção dos dados do sistema tradicional, primeiramente se buscaram dados provenientes de fontes consagradas, obtendo-se duas referências principais:

(a) TCPO (PINI, 2017), tabela de composições orçamentárias utilizada em larga escala no cenário nacional; e

(b) Sinapi (2017), plataforma utilizada como referência de obras e serviços de engenharia, contratados e executados com recursos federais.

Entretanto, como essas referências utilizam dados médios obtidos a partir de obras em todo o território nacional, considerando diferentes tipos de obras, optou-se pela utilização dos dados provenientes de uma planilha própria desenvolvida por um dos autores deste trabalho. Essa referência contém dados empíricos de produtividade de mão de obra para empreendimentos com fins de moradia similares aos analisados nos estudos de caso e desenvolvidos por uma incorporadora com atuação nacional posicionada entre as dez maiores construtoras do Brasil de acordo com o Ranking ITC (RANKING..., 2016). Essa planilha foi desenvolvida a partir de dados coletados em campo, por meio de visitas regulares (tipicamente mensais), em quinze empreendimentos, localizados nas cidades de Campinas, SP, São Paulo, SP, Porto
Alegre, RS, e Rio de Janeiro, RJ. Os dados foram obtidos via observações nos canteiros de obras e informações provenientes das equipes de planejamento dos empreendimentos e de subcontratados. Em todos os casos as atividades inerentes ao sistema tradicional foram desenvolvidas por equipes terceirizadas. A Tabela 1 apresenta os dados obtidos do TCPO (PINI, 2017), do Sinapi (2017) e da planilha própria adotada, destacando os números adotados para o presente trabalho. Assim, a RUP adotada para o sistema tradicional foi de $2,96 \mathrm{Hh} / \mathrm{m}^{2}$.

As RUPs obtidas para o sistema tradicional e para o LSF consideraram as etapas de preparação dos materiais e aplicação dos sistemas, desprezando as etapas de movimentação de materiais e montagens de andaimes. Ainda que a montagem de andaimes possa ser considerada como crítica em ambos os sistemas, a ponto de necessitar de grande quantidade de $\mathrm{Hh}$ para ser desenvolvida, esta foi desconsiderada com a justificativa de usualmente ser uma etapa desenvolvida por equipes terceirizadas distintas das equipes responsáveis pela montagem e aplicação dos sistemas em si, o que poderia alterar consideravelmente os índices coletados. De forma complementar, nos quatro estudos de caso analisados, além de não ser possível obter os dados de consumo de mão de obra para essa etapa, os andaimes utilizados foram de tipos diferentes. No estudo de caso A andaimes do tipo "fachadeiros" foram montados de forma antecipada por equipes terceirizadas, sem envolvimento dos responsáveis pela montagem do LSF, pois serviram como elementos de proteção, em substituição às usuais bandejas de proteção externas, o que consumiu mais tempo para sua montagem do que o necessário para a aplicação do LSF. Andaimes metálicos tubulares simples foram utilizados no estudo de caso $\mathrm{B}$, visto que a aplicação do sistema ocorreu no pavimento térreo, que continha pé-direito duplo. Nos estudos de caso C e D utilizou-se plataforma cremalheira elétrica, também montada por equipe terceirizada. Dessa forma, justifica-se a desconsideração desta etapa a fim de se evitarem distorções nas comparações das RUPs obtidas.

Tabela 1 - RUP adotada para o sistema tradicional (em $\mathrm{Hh} / \mathrm{m}^{2}$ )

\begin{tabular}{l|c|c|c|c}
\hline \multicolumn{1}{c|}{ Atividades } & $\begin{array}{c}\text { TCPO } \\
(\mathbf{2 0 1 7})\end{array}$ & $\begin{array}{c}\text { Sinapi } \\
(\mathbf{2 0 1 7})\end{array}$ & $\begin{array}{c}\text { Planilha } \\
\text { própria }\end{array}$ & $\begin{array}{c}\text { RUP } \\
\text { adotada }\end{array}$ \\
\hline Alvenaria borda externa (espessura 19 cm) & 1,30 & 1,48 & 1,15 & $\mathbf{1 , 1 5}$ \\
Chapisco externo & 0,20 & 0,16 & 0,21 & $\mathbf{0 , 2 1}$ \\
Argamassa revestimento externo & 1,26 & 1,46 & 1,05 & $\mathbf{1 , 0 5}$ \\
Gesso liso interno & 0,63 & 0,75 & 0,55 & $\mathbf{0 , 5 5}$ \\
\hline Total & $\mathbf{3 , 3 9}$ & $\mathbf{3 , 8 5}$ & $\mathbf{2 , 9 6}$ & $\mathbf{2 , 9 6}$ \\
\hline
\end{tabular}


Para as análises de geração de resíduos e consumo de água foram utilizados documentos baseados na Política Nacional de Resíduos Sólidos (PNRS) (BRASIL, 2010), Conama $n^{\circ} 307$, Conama $n^{\circ} 348$ (CONSELHO..., 2004), Sinduscon (SINDICATO..., 2005) e catálogos técnicos de fornecedores. Para a análise dos resíduos foram utilizados dados coletados em campo e informações nos manuais e catálogos para o cálculo da massa de resíduos gerada por cada um dos sistemas analisados neste trabalho. Em relação ao consumo de água, foram utilizados dados referentes ao volume de água necessário para o preparo dos materiais. Pelo fato se ser um item complexo para a real apuração do consumo no canteiro de obras, a água utilizada para lavagem de equipamentos e ferramentas não foi considerada no cálculo dos índices de consumo do LSF e do sistema tradicional.

\section{Resultados}

A seguir são apresentados os resultados obtidos por meio da análise dos estudos de caso.

\section{Estudo de caso A}

Para a análise de redução de mão de obra foram coletados dados referentes às torres I e III, que estavam em execução no momento da coleta de dados, agregando as atividades inerentes ao LSF em quatro etapas principais, conforme apresentado na Tabela 2. Os dados foram obtidos em entrevista realizada com a diretora do empreendimento e nas visitas realizadas em campo, a partir de informações disponibilizadas pela equipe técnica do empreendimento e por subcontratados. Além das etapas presentes na Tabela 2, a empresa responsável pela execução do empreendimento optou por uma argamassa especial no preenchimento de vãos internos do LSF. Entretanto, a fim de se manter um padrão de comparação com os demais estudos de caso, essa atividade foi desconsiderada na obtenção da RUP do LSF.

Numa média composta pelos dados das duas torres, chegou-se à RUP média de $1,11 \mathrm{Hh} / \mathrm{m}^{2}$ para a execução do sistema LSF. Extrapolando-se esse índice para a quantidade total de LSF utilizada no empreendimento $\left(15.000 \mathrm{~m}^{2}\right)$, obtiveram-se 16.650 Hh. Adotando-se a RUP do sistema tradicional, de $2,96 \mathrm{Hh} / \mathrm{m}^{2}$, e multiplicando-se esse índice pela quantidade de $15.000 \mathrm{~m}^{2}$, obtiveram-se $44.400 \mathrm{Hh}$. Assim, constatou-se que a adoção do LSF como elemento de fachada poderia representar uma redução de $27.750 \mathrm{Hh}$, ou 62,5\% a menos em comparação ao sistema tradicional.

Em relação à análise de geração de resíduos, calculou-se a massa dos resíduos gerados pelo sistema tradicional considerando-se blocos de concreto, revestimento externo com espessura média de $4 \mathrm{~cm}$ e revestimento interno com espessura média de $2,0 \mathrm{~cm}$, chegando-se a uma massa total de $3.000 \mathrm{t}$ para a execução das quatro torres. Com base em informações obtidas na descrição executiva do empreendimento, a qual simulava a comparação do sistema tradicional com o LSF, a empresa responsável pela execução da obra informou que a geração prevista de resíduos era da ordem de $10 \%$ para o sistema de fachada tradicional, incluindo o revestimento interno aplicado nas alvenarias de borda das torres, representando uma massa de 300 t de resíduos de materiais de construção.

Tabela 2 - RUPs obtidas para o sistema LSF, estudo de caso A

\begin{tabular}{l|c|c|c}
\hline \multicolumn{1}{c}{ Atividades } & \multicolumn{3}{c}{ RUPs obtidas (em Hh/m $\mathbf{2}^{\mathbf{2}}$} \\
\cline { 2 - 4 } & RUP Torre I & RUP Torre III & RUP Média \\
\hline Estruturação (guias e montantes) & 0,44 & 0,38 & 0,41 \\
Camada impermeável + plaqueamento externo & 0,34 & 0,32 & 0,33 \\
Acabamentos (basecoat) & 0,14 & 0,14 & 0,14 \\
Plaqueamento interno & 0,24 & 0,24 & 0,24 \\
\hline Total & $\mathbf{1 , 1 6}$ & $\mathbf{1 , 0 6}$ & $\mathbf{1 , 1 1}$ \\
\hline
\end{tabular}

52 Olivieri, H.; Barbosa, I. C. A.; Rocha, A. C. da; Granja, A. D.; Fontanini, P. S. P. 
Em relação aos resíduos gerados pelo LSF, a massa foi obtida a partir de dados extraídos do manual técnico de fornecedores, que, quando multiplicados por $15.000 \mathrm{~m}^{2}$, representam a massa total de 750 t. A empresa responsável pela execução da obra relatou que, considerando todos os elementos inerentes ao sistema, as perdas do LSF somaram $20 \%$, provenientes principalmente do "requadros" de vãos (cortes realizados), além do efeito da curva de aprendizagem no uso do sistema, visto que este foi o primeiro empreendimento residencial da empresa na qual se utilizou o sistema LSF. Os dados foram extraídos a partir do número de caçambas utilizadas para o descarte de materiais. Assim, embora o LSF tenha apresentado um porcentual maior de perdas $(20 \%)$ em comparação ao tradicional (10\%), em termos de volume computou-se uma massa de $150 \mathrm{t}$ de resíduos de LSF e de 300 t para o sistema tradicional, ou seja, uma redução de $50 \%$ da massa de resíduos quando da utilização do LSF. Por meio dos dados coletados, não foi possível obter um comparativo em termos de volume de resíduos (em metros cúbicos) entre o LSF e o sistema tradicional, limitando-se a análise à massa de resíduos. Entretanto, esse comparativo pode ser realizado em estudos futuros, visto que o LSF possui elementos leves que geram grande volume (em metros cúbicos), enquanto o sistema tradicional gera resíduos com maior massa (peso). De forma complementar, há que se considerar a possibilidade de reciclagem no próprio canteiro de obras de boa parte dos resíduos gerados pelo sistema tradicional.

Para a análise do consumo de água, utilizou-se os volumes considerados no orçamento executivo (planejado) do empreendimento, disponibilizado pela empresa, e em índices de consumos disponíveis em material técnico de fabricantes. Para o sistema tradicional considerou-se o volume de água necessária para a execução de alvenarias externas, gesso liso interno e argamassa externa, incluindo chapisco, limpeza e argamassa cimentícia. Para o LSF considerou-se a quantidade de água necessária para as etapas de tratamento de juntas e basecoat (revestimento externo).

No processo tradicional considerou-se o consumo de $17 \mathrm{~kg} / \mathrm{m}^{2}$ de argamassa para a execução de alvenarias, de $16 \mathrm{~kg} / \mathrm{m}^{2}$ para os revestimentos de gesso liso interno, e de $72 \mathrm{~kg} / \mathrm{m}^{2}$ para a execução de revestimento externo, adotando-se uma espessura média de $4 \mathrm{~cm}$. Para a quantidade total de $15.000 \mathrm{~m}^{2}$ de fachada, chegou-se ao montante total de argamassa de $1.575 \mathrm{t}$. Utilizando-se dados de fornecedor especializado em argamassa (VOTOMASSA, 2012), considerou-se o consumo de $0,16 \mathrm{~L}$ de água por quilo de argamassa. Para a etapa de gesso liso interno, considerou-se a quantidade de $12.000 \mathrm{~m}^{2}$ de aplicação, com um consumo de 1,0 L de água por quilo de gesso. Assim, avaliando-se o sistema tradicional, chegouse ao consumo total de $213.600 \mathrm{~L}$ de água para a execução de argamassas e de $192.000 \mathrm{~L}$ para a execução de gesso liso. No sistema LSF considerou-se o consumo de água indicado pelo fornecedor do sistema (KNAUF, 2016): 0,47 L/m² para o tratamento de juntas e $1,3 \mathrm{~L} / \mathrm{m}^{2}$ para a etapa de basecoat (revestimento), totalizando $1,77 \mathrm{~L} / \mathrm{m}^{2}$ de fachada. Multiplicando-se este índice pela quantidade total de fachada, obteve-se a quantidade de $26.550 \mathrm{~L}$ de água, uma redução significativa de $93,5 \%$ no volume de água empregado quando comparado ao sistema tradicional. Neste empreendimento, não foi possível obter a informação do volume total de água utilizado, incluindo todas as operações de canteiro, o que poderia contribuir com uma análise do impacto que o consumo reduzido a partir da utilização do LSF poderia representar no empreendimento como um todo.

\section{Estudo de caso B}

Para a análise de redução de mão de obra foram coletados dados com o gerente técnico do empreendimento e a equipe responsável pela aplicação do LSF. Devido ao fato de a aplicação ser realizada nos pavimentos inferiores, com menor movimentação de materiais e maior facilidade de acesso aos pavimentos, optou-se por iniciar a aplicação com uma equipe básica de dois operários, sendo um montador e um ajudante. Após a primeira semana de trabalho, e considerando-se o aprendizado realizado nos primeiros dias, optou-se por alocar uma equipe adicional semelhante à primeira equipe, totalizando-se dois montadores e dois ajudantes. A Figura 2 ilustra a vista frontal de uma das torres do empreendimento e um detalhe da instalação das etapas de perfis metálicos e chapas cimentícias no primeiro pavimento da Torre I. Por ser aplicado em uma área com pé-direito duplo, o sistema foi montado externamente à estrutura de concreto, com as guias inferiores posicionadas sobre o piso de concreto, e as guias superiores fixadas diretamente nas lajes.

A RUP obtida foi de $0,8 \mathrm{Hh} / \mathrm{m}^{2}$, o que representa uma área produzida de $20 \mathrm{~m}^{2}$ por dia para cada equipe. Multiplicando-se esse índice pela quantidade total de LSF utilizada no empreendimento $\left(800 \mathrm{~m}^{2}\right)$, chegou-se ao total de 640 Hh. Para efeito de comparação com o sistema tradicional de fachadas, utilizando-se a RUP de $2,96 \mathrm{Hh} / \mathrm{m}^{2}$ e multiplicando-se esta pela quantidade de área de LSF realizada, chegou-se ao 
total de 2.368 Hh. Assim, constata-se que a adoção do LSF como elemento de fachada representou uma redução de $1.728 \mathrm{Hh}$, ou $73 \%$ a menos quando comparada ao processo tradicional.

\section{Estudo de caso C}

Para a análise de redução de mão de obra os dados coletados referentes ao LSF foram agrupados em cinco etapas principais, conforme apresentado na Tabela 3. Os dados foram coletados com a equipe técnica do empreendimento e a equipe de produção. A empresa subcontratada responsável pela execução do LSF possuía equipe de dez operários alocada no canteiro de obras, realizando as atividades de estruturação, camada impermeável e "plaqueamento" externo, tratamento de juntas de dilatação, aplicação de acabamentos externos e "plaqueamento" interno. Os operários foram capacitados a atuar de forma multidisciplinar, ou seja, poderiam desenvolver tarefas em todas as atividades. A RUP apurada para a execução do LSF foi de $0,97 \mathrm{Hh} / \mathrm{m}^{2}$. Comparando-se os dados do LSF com o sistema tradicional, que possui uma RUP de 2,96 $\mathrm{Hh} / \mathrm{m}^{2}$, conclui-se que neste empreendimento a adoção do LSF como sistema de fachadas representou uma redução $67,2 \%$ no consumo de mão de obra $\left(\mathrm{Hh} / \mathrm{m}^{2}\right)$.

\section{Estudo de caso D}

Em relação à análise dos prazos, foram desenvolvidos dois cronogramas, o primeiro considerando o processo tradicional de fachadas e o segundo considerando o sistema LSF. Ambos os cronogramas foram desenvolvidos no formato de cronograma de barras, utilizando-se o software MS Project $^{\circledR}$. As durações das atividades, o sequenciamento construtivo e os recursos foram definidos pela equipe que desenvolveu o estudo de viabilidade. O cronograma que considera o processo tradicional de fachadas contém 1.673 atividades, incluindo todo o escopo necessário para o desenvolvimento do empreendimento. O cronograma que considera o LSF contém 1.318 atividades, também considerando todo o escopo do empreendimento. Para fins do trabalho, foram selecionadas as atividades que possuem correlação direta com ambos os sistemas (tradicional e LSF) e fazem parte do caminho crítico do cronograma. No Quadro 2 são apresentadas as atividades e o sequenciamento construtivo adotado para a análise do LSF em comparação ao processo tradicional, destacando-se em negrito as atividades inerentes aos sistemas. A fim de se facilitarem a visualização e a análise, os cronogramas foram transformados em linhas de balanço (Figura 3) através do software Schedule Planner Standard, mantendo-se todas as premissas definidas nos cronogramas originais.

Figura 2 - Vista frontal de uma das torres e detalhe da instalação de perfis e chapa cimentícia

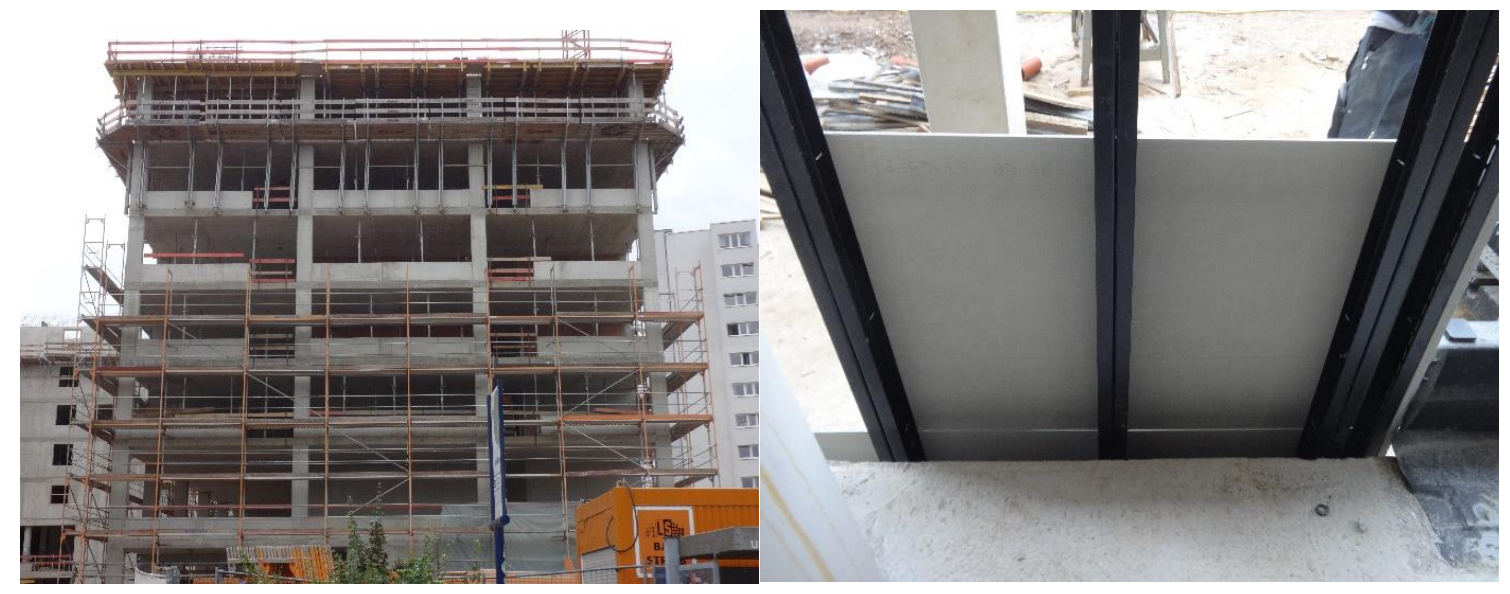

Tabela 3 - RUP obtida para o sistema LSF, estudo de caso C

\begin{tabular}{l|c}
\hline \multicolumn{1}{c|}{ Atividades } & RUP $\left(\mathbf{e m ~} \mathbf{H h} / \mathbf{m}^{\mathbf{2}}\right)$ \\
\hline Estruturação (guias e montantes) & 0,16 \\
Camada impermeável + plaqueamento externo & 0,13 \\
Tratamento de juntas & 0,05 \\
Acabamentos (basecoat) & 0,38 \\
Plaqueamento interno & 0,25 \\
\hline Total & $\mathbf{0 , 9 7}$ \\
\hline
\end{tabular}

54 Olivieri, H.; Barbosa, I. C. A.; Rocha, A. C. da; Granja, A. D.; Fontanini, P. S. P. 
Quadro 2 - Atividades e sequenciamento construtivo dos sistemas LSF e tradicional

\begin{tabular}{|c|c|}
\hline LSF & Tradicional \\
\hline $\begin{array}{l}\text { 1) Estrutura de concreto } \\
\text { 2) LSF, composto de guias, montantes, } \\
\text { camada impermeável, plaqueamento } \\
\text { externo/interno, tratamento de juntas e } \\
\text { basecoat (camada de revestimento } \\
\text { externo) } \\
\text { 3) Prumadas e ramais hidráulicos } \\
\text { 4) Drywall interno, incluindo shafts hidráulicos } \\
\text { 5) Contramarco metálico } \\
\text { 6) Esquadrias de alumínio } \\
\text { 7) Impermeabilização de áreas frias } \\
\text { 8) Contrapiso } \\
\text { 9) Revestimento cerâmico } \\
\text { 10) Portas de madeira } \\
\text { 11) Pintura interna } \\
\text { 12) Limpeza fina } \\
\text { 13) Pintura externa }\end{array}$ & $\begin{array}{l}\text { 1) Estrutura de concreto } \\
\text { 2) Alvenaria externa, com blocos de concreto ou } \\
\text { cerâmicos e telas de reforço } \\
\text { 3) Alvenaria interna } \\
\text { 4) Prumadas, ramais e shafts hidráulicos } \\
\text { 5) Impermeabilização de áreas frias } \\
\text { 6) Contrapiso } \\
\text { 7) Contramarco metálico } \\
\text { 8) Revestimento cerâmico } \\
\text { 9) Portas de madeira } \\
\text { 10) Pintura interna } \\
\text { 11) Limpeza fina } \\
\text { 12) Revestimento externo, composto de limpeza grossa } \\
\text { da fachada (remoção de arames, pregos e excessos } \\
\text { de concreto e argamassa), limpeza fina da fachada } \\
\text { (lavagem), chapisco externo e argamassa externa } \\
\text { 13) Esquadrias de alumínio } \\
\text { 14) Pintura externa }\end{array}$ \\
\hline
\end{tabular}

Nota: Legenda: atividades destacadas em negrito representam as atividades inerentes aos sistemas LSF e tradicional. Os números de 1 a 14 representam o sequenciamento construtivo adotado na análise dos cronogramas.

Figura 3 - Cronogramas das fachadas tradicional e LSF

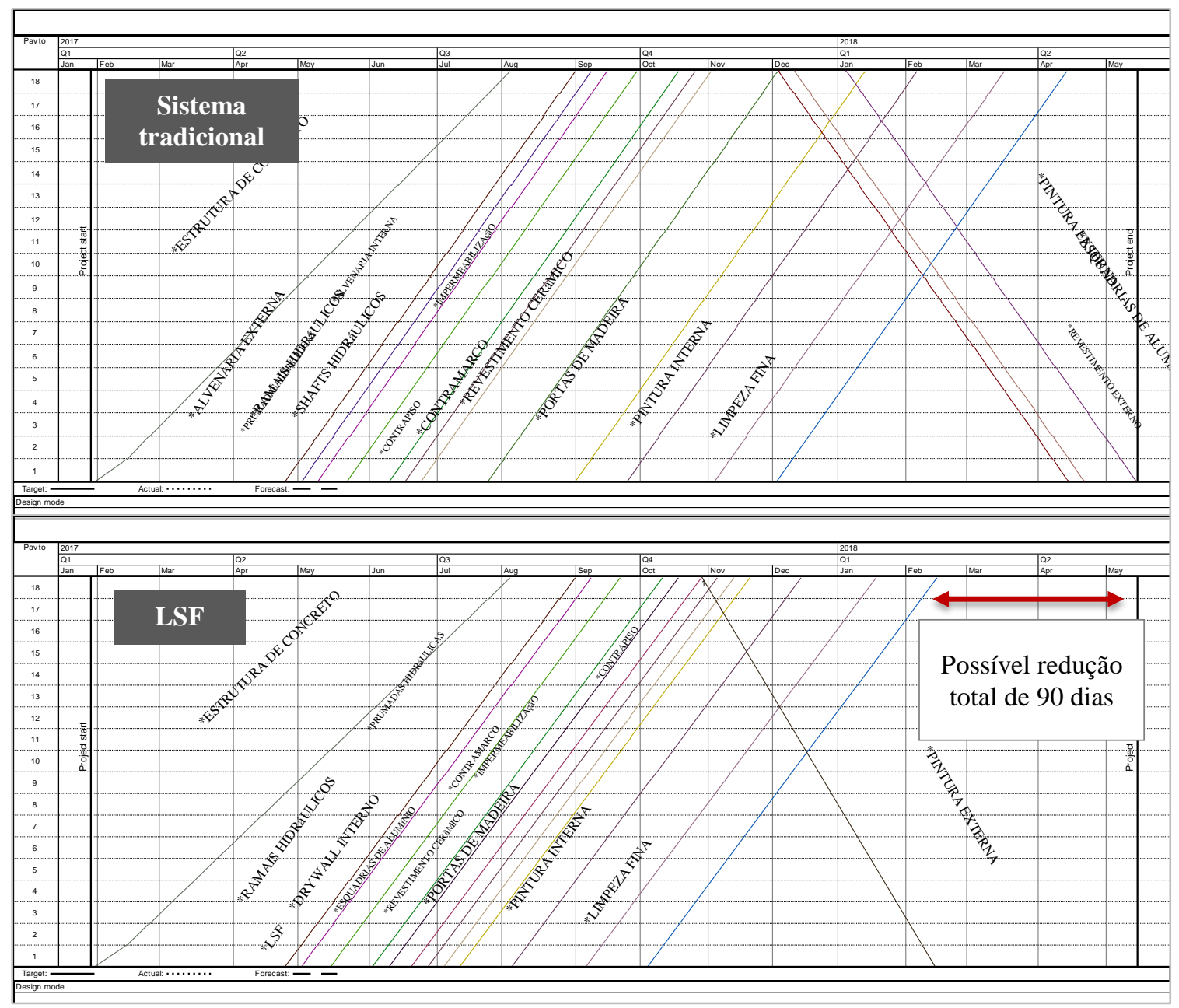


Analisando-se a Figura 3, constata-se uma possível redução de noventa dias no prazo de execução do empreendimento, a partir da utilização do LSF como elemento de fachada. Em tese, essa redução deve-se ao menor número de atividades necessárias para a execução do LSF e à instalação da atividade de "esquadrias de alumínio" de forma ascendente (de baixo para cima), permitindo a antecipação dos acabamentos externos na fachada, que, conforme abordado anteriormente, fazem parte do caminho crítico do empreendimento. Além disso, a instalação antecipada das esquadrias poderia proporcionar melhoria das condições de trabalho para as atividades de acabamentos internos, a partir de maior proteção às ações de intempéries, tais como chuvas e vento.

Outro fator que poderia contribuir para a redução de prazos foi a premissa adotada pela empresa que considera a execução, de forma ascendente, de um pavimento de LSF por semana, ou seja, uma quantidade aproximada de $423 \mathrm{~m}^{2}$ de LSF realizada a cada 7 dias, considerando-se as etapas de estruturação, plaqueamento, camada impermeável, tratamento de juntas e revestimentos. Em uma empresa especializada na execução do LSF (instalador) que participou do estudo de viabilidade dimensionou-se uma equipe de dez operários a fim de atender a essa demanda de produtividade. Considerando-se 8 horas de trabalho por dia para cada operário, chega-se à RUP estimada de $0,95 \mathrm{Hh} / \mathrm{m}^{2}$, uma potencial redução de $67,9 \%$ quando comparada ao sistema tradicional, que apresenta RUP de $2,96 \mathrm{Hh} / \mathrm{m}^{2}$.

Em relação à redução da geração de resíduos de materiais, dados do estudo de viabilidade analisado estimam um consumo total de 450,06 $\mathrm{t}$ de materiais para a execução dos $8.032 \mathrm{~m}^{2}$ de fachada em LSF, o que representa $56,04 \mathrm{~kg} / \mathrm{m}^{2}$ de fachada. Esses dados foram obtidos a partir de levantamento quantitativo, realizado por equipe interna da incorporadora, que considerou projetos executivos desenvolvidos para o estudo. Da mesma forma que ocorreu para o sistema LSF, foram levantados os quantitativos e pesos dos materiais que compõem o sistema tradicional de fachadas, utilizando-se projetos executivos desenvolvidos para o estudo e pesos de materiais estimados com base em informações de materiais técnicos de fornecedores. A massa total estimada para o sistema tradicional é de $1.865,45 \mathrm{t}$, ou $232,26 \mathrm{~kg} / \mathrm{m}^{2}$ de fachada.

Para o cálculo do montante estimado de resíduos da construção, adotou-se uma taxa de perda de $4 \%$ para o sistema LSF e de $14,1 \%$ para o resíduo de construção para o sistema tradicional. Para o caso do LSF, os dados foram obtidos de um subcontratado especializado na realização desse tipo de atividade, que participou do estudo de viabilidade desenvolvido e que possui dados históricos de empreendimentos semelhantes no qual prestou serviços. Para o sistema tradicional, considerou-se uma perda média de $13,9 \%$ para materiais secos e de $15,9 \%$ para água, obtendo-se a média ponderada de $14,1 \%$ para os materiais de uma forma geral. Dessa forma, a massa total de resíduos foi de 34,86 t para o sistema LSF e de 262,47 t para o sistema tradicional. Assim, o sistema LSF pode representar uma redução significativa de $86,7 \%$ na geração de resíduos da construção quando comparado ao sistema tradicional. Destaca-se também o tipo de resíduo gerado, uma vez que o resíduo de LSF é pertencente, quase em sua totalidade, à Classe $\mathrm{B}$ (Conama $n^{\circ}$ 307) (CONSELHO..., 2002), o que garante seu retorno na cadeia produtiva como um produto altamente reciclável por outras indústrias do setor da construção. Já o resíduo da construção gerado pelo método tradicional é pertencente à Classe A (Conama n ${ }^{\circ}$ 307) (CONSELHO..., 2002), que prevê sua maior aplicação como agregado reciclado em argamassas e concretos não estruturais. Esse tipo de reutilização e reciclagem necessita de processos de segregação, britagem e peneiramento antes de retornar ao processo produtivo novamente. Portanto, devem-se destacar as diferenças apresentadas na reutilização, reciclagem, destinação e disposição dos diferentes resíduos gerados em cada um dos casos (BRASIL, 2010).

Em relação à redução do consumo de água, o estudo de viabilidade considerou os consumos em volume indicados pelos fabricantes dos materiais utilizados em ambos os sistemas LSF e tradicional, chegando-se a um consumo de $142.111 \mathrm{~L}$ para o sistema tradicional e de $29.803 \mathrm{~L}$ para o sistema LSF. Dessa forma, o sistema LSF pode representar uma redução de $79,0 \%$ no consumo de água necessária para a realização das fachadas quando comparado ao sistema tradicional. Dados obtidos por meio da análise do orçamento executivo (planejado) mostram que o consumo total de água previsto para esse empreendimento seria de aproximadamente 2.265.000 L. Assim, a economia de cerca de $112.000 \mathrm{~L}$ proporcionada a partir da implementação do LSF representaria uma economia estimada em $4,9 \%$ em relação ao consumo total de água, valor este que pode ser considerado com baixa representatividade e baixo impacto no empreendimento.

\section{Discussão}

A Tabela 4 apresenta os principais resultados obtidos a partir dos estudos de caso analisados e dos quatro tópicos abordados no início da 
pesquisa: consumo de mão de obra, geração de resíduos, consumo de água e prazo de obra.

A redução do consumo de mão de obra pode ser constatada nos quatro estudos de caso analisados. Os principais fatores que contribuem para essa redução são a melhor logística proporcionada pelo sistema, o menor peso dos materiais e a formação de equipes multitarefa. A variação mais representativa ocorreu no estudo de caso B (73\%), que considerou a aplicação do LSF em pavimentos inferiores, destacando-se a facilidade na logística de abastecimento e na montagem de equipamentos de suporte para a realização das atividades, tais como andaimes metálicos. Para o caso de empresas que decidam utilizar o LSF em seus canteiros, recomenda-se que índices próprios sejam apurados, a fim de se obterem comparações com o sistema tradicional e com trabalhos que contenham índices sobre o LSF.

O menor peso próprio do LSF, quando comparado ao tradicional, aumenta a produtividade da mão de obra e facilita sua logística de obra, visto que elementos mais leves podem ser movimentados de forma mais ágil e independente de equipamentos e máquinas. A utilização de elementos préfabricados, como os perfis e as guias metálicas, proporciona uma montagem mais rápida e eficiente. As guias metálicas são os elementos que determinam o correto posicionamento para a instalação do sistema. Assim, a partir da instalação desses elementos, despende-se menos tempo com conferências de prumos e nivelamentos, evitandose interrupções e paralizações desnecessárias.

A utilização de equipes multifuncionais, em que os operários estão capacitados a realizar todas as atividades inerentes ao sistema, pode proporcionar perdas menores com tempo de espera nas frentes de serviço, fato que resulta no aumento da produtividade da equipe. As principais evidências da utilização dessas equipes foram constatadas nos estudos de caso A e C. Ainda que o estudo de caso $\mathrm{D}$ represente um estudo de viabilidade, a premissa de utilização de equipes multitarefa permitiu o dimensionamento da equipe de forma a cumprir a meta estipulada de um pavimento por semana, considerando todas as atividades inerentes ao LSF.

Um menor consumo de mão de obra pode representar ganhos significativos em termos de custos e consumo de recursos. A partir dessa redução podem-se dimensionar canteiros mais enxutos e eficientes. Um menor número de operários no canteiro pode representar uma queda no consumo de volume de água, na produção de esgoto e no consumo de energia elétrica. Além disso, pode-se inferir que um canteiro de obras com uma quantidade menor de operários pode ser gerenciado e supervisionado de forma mais eficiente pela equipe do empreendimento.

A redução na geração de resíduos de construção civil foi evidenciada nos estudos de caso A e D, podendo representar uma gestão mais eficiente desses insumos nos canteiros de obras. A partir dessa redução evitam-se movimentações desnecessárias de mão de obra e de materiais para a remoção e destinação dos resíduos, o que proporciona um uso mais efetivo de equipamentos de logística, como elevadores de carga, que passam a ser utilizados por mais tempo em operações voltadas diretamente à produção. Em relação ao estudo de caso $\mathrm{A}$, ainda que tenha ocorrido redução da ordem de $50 \%$ na geração de resíduos em relação à massa, nota-se que a taxa de perdas adotada no sistema LSF foi de $20 \%$, considerada alta para um sistema semiindustrializado. Os principais fatores para essa taxa são o efeito de curva de aprendizagem, visto ter sido a primeira obra em que o sistema foi utilizado pela empresa, além da decisão da equipe técnica do empreendimento de instalar todo o "plaqueamento" externo sem recortes, cobrindo toda a superfície dos vãos de esquadrias e portas, para o posterior corte e remoção desse material. Portanto, acredita-se que existe uma grande oportunidade de melhoria neste item, que poderia representar uma redução maior na geração de resíduos de LSF em obras posteriores.

\section{Tabela 4 - Principais resultados obtidos a partir dos estudos de caso}

\begin{tabular}{l|l}
\hline \multicolumn{1}{c|}{ Tópico } & \multicolumn{1}{c}{ Principais resultados obtidos a partir da utilização do LSF } \\
\hline Consumo de mão de obra & $\begin{array}{l}\text { Redução de 62,5\% (estudo caso A), 73\% (estudo de caso B), 67,2\% } \\
\text { (estudo de caso C) e possível redução de 67,9\% (estudo de caso D) }\end{array}$ \\
\hline Geração de resíduos & $\begin{array}{l}\text { Redução de 50\% da massa de resíduos (estudo de caso A) e redução } \\
\text { estimada de } 86,7 \% \text { (estudo de caso D) }\end{array}$ \\
\hline Consumo de água & $\begin{array}{l}\text { Redução de } 93,5 \% \text { do volume de água consumida (estudo de caso A) } \\
\text { e redução estimada de 79,0\% (estudo de caso D) }\end{array}$ \\
\hline Prazo de obra & Possível redução de 3 meses no prazo de obra (estudo de caso D) \\
\hline
\end{tabular}


Em relação ao volume de consumo de água, os índices de redução apresentados nos estudos de caso A e D são bastante representativos $(93,5 \%$ e $79,0 \%$ respectivamente), ainda mais por se referir a um recurso com escassez cada vez mais evidente, principalmente nas grandes cidades. $\mathrm{O}$ volume de consumo de água sugerido nos manuais dos fabricantes de argamassa e gesso foi adotado como referência em ambos os estudos de caso, A e D, e pode ser considerado relevante para mensurar a realidade do canteiro de obras, visto tratar-se de instruções técnicas para o preparo de produtos, e não apenas instruções para promover os benefícios de tais produtos. A análise realizada no estudo de caso D indicou baixa representatividade da economia de água gerada a partir da utilização do LSF diante do consumo total de água do empreendimento, o que, por consequência, representaria baixa redução nos custos totais. Assim, o fator "menor consumo de água" não tenderia a ser um fator decisório ao se analisar a viabilidade de implementação do sistema LSF.

A possível redução dos prazos de obra, destacada no estudo de caso $\mathrm{D}$, pode proporcionar reduções nos custos indiretos de administração das obras, além de um custo menor para as despesas com canteiro de obras. De forma complementar, a possibilidade de realizar praticamente todas as atividades de forma ascendente (de baixo para cima) pode melhorar as condições de fluxo de trabalho para as atividades, além de permitir melhor controle da produção e uma operação mais eficiente dos equipamentos de logística. A instalação antecipada de esquadrias, se comparada ao processo tradicional, pode proporcionar melhor proteção aos ambientes internos, auxiliando no desenvolvimento das atividades de acabamentos e evitando retrabalhos desnecessários.

\section{Conclusões}

A utilização do LSF como sistema de fachadas pode representar melhores condições para o gerenciamento de insumos e de operações nos canteiros de obras. Além da obtenção de índices relativos ao consumo de mão de obra, melhorias significativas foram evidenciadas a partir da análise dos estudos de caso, tais como redução no consumo de mão de obra, menor volume na geração de resíduos de construção civil, menor volume de consumo de água e possível redução dos prazos de construção. A partir dessas melhorias, de forma indireta outros itens podem ser beneficiados, como a utilização mais eficiente de equipamentos de logística, redução dos custos de operação dos canteiros e eventual redução de custos indiretos para o gerenciamento dos empreendimentos.
A proposição de que o LSF contribui para a redução do consumo de mão de obra nos canteiros pôde ser comprovada a partir dos resultados obtidos nos quatro estudos de caso, com taxas de redução variando de $62,5 \%$ (estudo de caso $\mathrm{A}$ ) a $73 \%$ (estudo de caso B). Essa redução poderia ser intensificada no caso da pré-fabricação dos elementos, que seriam produzidos em condições mais favoráveis à industrialização - ambiente externo controlado - e permitiriam uma montagem mais rápida, além de uma qualidade técnica superior do sistema. Neste caso, estudos adicionais são necessários para a obtenção de novos comparativos.

Ao se partir da premissa de implementação do LSF, pode-se obter uma redução do volume da geração de resíduos de construção inerentes ao sistema de fachadas. Essa diminuição poderia causar impactos positivos diretos na operação dos canteiros, como a melhor organização e utilização dos equipamentos de logística, que passam a operar com maior intensidade em atividades voltadas diretamente ao processo de produção, além de uma diminuição significativa da quantidade de caçambas necessárias para a remoção dos resíduos. Entretanto, há que se considerar que o sistema tradicional tem apresentado reduções nos índices de resíduos devido a uma gestão mais eficiente das empresas e à aplicação de novas tecnologias de materiais e equipamentos. Assim, estudos complementares são necessários para a corroboração das diferenças de resultados entre os dois sistemas.

O sistema LSF é considerado um sistema a seco, com baixo consumo de volume de água. Essa premissa pôde ser ressaltada a partir dos estudos de caso A e D, com reduções de consumo da água na ordem de $93,5 \%$ e 79,0\% respectivamente. Assim, além de tornar os canteiros com condições mais favoráveis à melhor utilização dos recursos naturais, recursos vitais escassos podem ser reduzidos drasticamente e utilizados de forma mais consciente. Entretanto, a baixa representatividade dessa redução ante o consumo total de água do empreendimento, conforme descrito no estudo de caso D, poderia ser um fator pouco estimulante num processo de decisão quanto ao uso do LSF.

A possível redução dos prazos de obra, evidenciada no estudo de caso $\mathrm{D}$, poderia beneficiar as empresas incorporadoras e construtoras em decisões, tais como entrega antecipada dos empreendimentos aos clientes ou postergação do início das obras, cumprindo-se os prazos estipulados com os clientes e melhorandose as condições do fluxo de caixa. Além da efetiva redução dos prazos, o LSF pode proporcionar melhores condições de fluxo de trabalho para as 
equipes, com um sequenciamento mais organizado das atividades.

As principais limitações deste trabalho estão relacionadas à coleta de dados por análises de documentos e entrevistas com profissionais atuantes nos estudos de caso, com pouca quantidade de dados coletados diretamente em campo pelos autores. De forma complementar, o trabalho limitou-se à análise de empreendimentos para fins de moradia permanente ou temporária, não considerando, por exemplo, obras para fins industriais e comerciais. Pelo fato de os empreendimentos analisados possuírem características diferentes entre si, como o sistema estrutural, a quantidade de pavimentos e a quantidade de LSF utilizada, pesquisas futuras poderiam incluir estudos de caso com características semelhantes. Nestes poderiam ser analisadas eventuais reduções de utilização de mão de obra e dos prazos totais a partir da implementação do LSF, considerando-se, inclusive, a montagem e desmontagem de andaimes na análise de produtividade da mão de obra.

\section{Referências}

BABIČ, N. Č. et al. Integrating Resource Production and Construction Using BIM.

Automation in Construction, v. 19, n. 5, p. 539543, 2010.

BRASIL. Lei federal $\mathrm{N}^{\circ} 12.305$, de 2 de agosto de 2010, que institui a Política Nacional de Resíduos Sólidos. Diário Oficial da União, Brasília, DF, 2 de agosto de 2010.

BRASIL. MINISTÉRIO DAS CIDADES.

Diretriz SINAT No 009, revisão 1 - sistema de vedação vertical externa, sem função estrutural, multicamadas, formado por perfis leves de aço zincado e fechamentos em chapas delgadas com revestimento de argamassa. Brasília, 2016.

CARDOSO, S. S. Tecnologia Construtiva de Fachada em Chapas Delgadas Estruturadas em Light Steel Framing. São Paulo, 2016.

Dissertação (Mestrado em Engenharia Civil) Escola de Engenharia, Universidade de São Paulo, São Paulo, 2016.

CONSELHO NACIONAL DO MEIO

AMBIENTE. Resolução N $\mathbf{N}^{\mathbf{3 0 7}}$, de 5 julho de 2002. Brasília, 2002.

CONSELHO NACIONAL DO MEIO

AMBIENTE. Resolução No 348, de 16 agosto de 2004. Brasília, 2004.
FREITAS, A. M. S.; CRASTO, R. C. M. Steel Framing: arquitetura. Rio de Janeiro: Instituto do Aço Brasil; CBCA, 2006. (Série Manuais da Construção em Aço).

GOMES, A. P.; SOUZA, H. A.; TRIBESS, A. Impact of Thermal Bridging on the Performance of Buildings Using Light Steel Framing in Brazil. Applied Thermal Engineering, v. 52, p. 84-89, 2013.

KNAUF. Aquapanel ${ }^{\circledR}$ Exterior Basecoat. Material técnico. Berlin, 2016.

LAWSON, R. M.; OGDEN, R. G. 'Hybrid' Light Steel Panel and Modular Systems. Thin-Walled Structures, v. 46, p. 720-730, 2008.

MEDEIROS, J. S. et al. Tecnologias de Vedação e Revestimento Para Fachadas. Rio de Janeiro: Instituto do Aço Brasil; CBCA, 2014. (Série Manuais da Construção em Aço).

MEJICOVSKY, T.; SETTLEMYRE, K. Achieving Innovation in Facades. Architectural Engineering, 2003.

PATTON, M. Q. Qualitative Evaluation and

Research Methods. Thousand Oaks: Sage Publications, 1990.

PÉREZ, C. T.; COSTA, D. B.; GONÇALVES, J. P. Identificação, Mensuração e Caracterização das Perdas por Transporte em Processos Construtivos. Ambiente Construído, Porto Alegre, v. 16, n. 1, p. 243-263, jan./mar. 2016.

PINI. Tabela de Composição de Preços Para Orçamentos. São Paulo: Pini, 2017.

RANKING ITC - INTELIGÊNCIA EMPRESARIAL DA CONSTRUÇÃO. As Maiores 100 Construtoras do Brasil, 2016. Disponível em: <http://rankingitc.com.br/rankingitc-2015/>. Acesso em: 08 ago. 2017.

ROCHA, A. C. Análise Comparativa de Planejamento e Custo de Fachadas de Edifício de Múltiplos Pavimentos Com as Tecnologias Tradicional E com Chapas Delgadas Estruturadas em Light Steel Framing. São Paulo, 2017. Dissertação (Mestrado em Engenharia Civil) - Escola Politécnica, Universidade de São Paulo, São Paulo, 2017.

SANTIAGO, A. K. O Uso do Sistema Light Steel Framing Associado a Outros Sistemas Construtivos Como Fechamento Vertical Externo Não Estrutural. Ouro Preto, 2008. Tese (Doutorado em Engenharia Civil) - Escola de Engenharia, Universidade Federal de Ouro Preto, Ouro Preto, 2008. 
SANTIAGO, A. K.; ARAÚJO, E. C. Sistema Light Steel Framing Como Fechamento Externo Vertical Industrializado. In: CONGRESSO LATINO-AMERICANO DA CONSTRUÇÃO METÁllCA, 3., São Paulo, 2008. Anais... São Paulo, 2008.

SILVA, F. B.; BARROS, M. M. S. B. Planejamento de Processos de Construção Para a Produção Industruializada em Larga Escala de Edifícios Habitacionais: um modelo baseado na indústria de manufatura. In: ENCONTRO

NACIONAL DE TECNOLOGIA DO AMBIENTE CONSTRUÍDO, 15., Juiz de Fora, 2012. Anais... Juiz de Fora, 2012.

\section{SISTEMA NACIONAL DE PESQUISAS DE} CUSTOS E ÍNDICES DA CONSTRUÇÃO CIVIL. [Sinapi]. Disponível em: http://www.caixa.gov.br/poder-publico/apoiopoder-publico/sinapi/Paginas/default.aspx $>$. Acesso em: 18 fev. 2017.

SINDICATO DA INDÚSTRIA DA CONSTRUÇÃO CIVIL DO ESTADO DE SÃO PAULO. Gestão Ambiental de Resíduos da Construção Civil: a experiência do Sinduscon-SP. São Paulo, 2005.

SOARES, N. et al. Multi-Dimensional Optimization of the Incorporation of PCMDrywalls in Lightweight Steel-Framed Residential Buildings in Different Climates. Energy and Buildings, v. 70, p. 411-421, 2014.
SOUZA, U. E. L. Como Reduzir Perdas nos Canteiros: manual de gestão do consumo de materiais na construção civil. São Paulo: Pini, 2006.

TUZZO, S. A.; BRAGA, C. F. O Processo de Triangulação da Pesquisa Qualitativa: o metafenômeno como gênese. Revista Pesquisa Qualitativa, v. 4, n. 5, p. 140-158, 2016.

VELJKOVIC, M.; JOHANSSON, B. Light Steel Framing for Residential Buildings. Thin-Walled Structures, v. 44, p. 1272-1279, 2006.

VIVAN, A. L.; PALIARI, J. C. Design for Assembly Aplicado ao Projeto de Habitações em Light Steel Frame. Ambiente Construído, Porto Alegre, v. 12, n. 4, p. 101-115, out./dez. 2012.

VOTOMASSA. Massa Pronta: ficha técnica de produto. 2012.

WAY, A. G. L.; LAWSON, R. M. Design and Installation of Light Steel External Wall Systems. Technical Report. SDI document ED017. Steel Construction Institute (SCI). London, 2013.

YIN, R. K. Case Study Research: design and methods. Beverly Hills: Sage, 2013.

ZANELATTO, K. C.; BARROS, M. M. S. B.; SABBATINI, F. H. Avaliação da Influência Técnica de Execução no Comportamento de Revestimento de Argamassa Aplicado Com Projeção Mecânica Contínua. Ambiente Construído, Porto Alegre, v. 13, n. 2, p. 87-109, jul./set. 2013.

Hylton Olivieri

Aalto University | Rakentajanaukio 4A | Espoo - Finland | PO Box 12100 | Tel.: +358503229579 | E-mail: hylton.olivieri@gmail.com

\section{Ivan Carlos Alves Barbosa}

Rossi Residencial S/A | Rua Alexandre Dumas, 1711, $3^{\circ}$ Andar, Chácara Santo Antonio | São Paulo - SP - Brasil | CEP 04714-004 | Tel: (11) 4058-2310 | E-mail: ivan.barbosa@me.com

\section{Antonio Carlos da Rocha}

ACR Assessoria e Planejamentos Ltda. | Rua Aguapeí, 694, Conj. 41, Vila Santo Estevão | São Paulo - SP - Brasil | CEP 03325-000 | Tel.: (11) 2673-7918 | E-mail: acrocha@acr.eng.br

\section{Ariovaldo Denis Granja}

Laboratório de Gerenciamento na Construção, Departamento de Arquitetura e Construção | Universidade Estadual de Campinas | Av. Albert Einstein, 951, Cidade Universitária Zeferino Vaz, Barão Geraldo | Campinas - SP - Brasil | Caixa Postal 6021 | CEP 13083-852 | Tel.: (19) 3521-2082 | E-mail: adgranja@fec.unicamp.br

Patricia Stella Pucharelli Fontanini

Departamento de Arquitetura e Construção | Universidade Estadual de Campinas | Tel.: (19) 3521-2469 | E-mail: patricia@fec.unicamp.br

\section{Revista Ambiente Construído}

Associação Nacional de Tecnologia do Ambiente Construído

Av. Osvaldo Aranha, $99-3^{\circ}$ andar, Centro

Porto Alegre - RS - Brasil

CEP $90035-190$

Telefone: +55 (51) 3308-4084

Fax: +55 (51) 3308-4054

www.seer.ufrgs.br/ambienteconstruido

E-mail: ambienteconstruido@ufrgs.br

60 Olivieri, H.; Barbosa, I. C. A.; Rocha, A. C. da; Granja, A. D.; Fontanini, P. S. P. 